\title{
Komposisi Komunitas Serangga Aphidophaga dan Coccidophaga pada Agroekosistem Kacang Panjang (Vigna sinensis l.) di Kabupaten Garut
}

\author{
Lindung Tri Puspasari*, M. Suhunan Sianipar, dan Sri Hartati \\ Departemen Hama dan Penyakit Tumbuhan, Fakultas Pertanian, Universitas Padjadjaran \\ Jatinangor-Sumedang 45363 \\ *Alamat korespondensi: lindung.tri@unpad.ac.id
}

\begin{abstract}
Composition of Aphidophaga and Coccidophaga Insect Communities on Long Bean Agroecosystem (Vigna sismensis L.) at Garut Regency
\end{abstract}

The research about Aphidophaga and Coccidophaga insect composition comunity on long beans (Vigna sinensis L.) agroecosystems was done in the month of April to November 2011 in Haruman Village, Leles District, Garut Regency. Research was conducted in the form of surveys which were done by collecting insects directly and using various traps ie yellow traps board, fitfall traps, and nets swinging. The dominant insect pest that found was Aphis craccivora which causing percentage of damage to the plants ranging from $20 \%$ to $90 \%$. Types of aphidophaga and coccidophaga found were belong to the Order of Coleoptera : Family Coccinellidae Menochilus sexmaculatus, Micraspis sp., Harmonia sp., Verania lineata, Curinus coeruleus, Scymnus sp., Coccinella transversalis); the Order of Diptera : Family Syrphidae namely Ischiodon scutellaris, Neuroptera: Family Hemerobiidae; the Order of Diptera : Family Cecidomyiidae Aphidoletes aphidimyza; and there was also Carabidae beetles of the Order Coleoptera with species diversity index wasl relatively low. The highest abundance of predators of coccidophaga and aphidophaga group was dominated by Ischiodon scutellaris and Menochilus sexmaculatus.

Key words: Diversity, Abundance, Dominant species, Insect pests

\begin{abstract}
ABSTRAK
Penelitian mengenai komposisi komunitas serangga aphidophaga dan coccidophaga pada Agroekosistem kacang panjang (Vigna sinensis (L.) telah dilaksanakan pada Bulan April-November 2011 di Desa Haruman Kecamatan Leles Kabupaten Garut. Penelitian dilakukan menggunakan metode survei dengan mengoleksi serangga secara langsung, dan menggunakan berbagai perangkap antara lain perangkap papan kuning, fitfall trap, dan jaring ayun. Serangga hama dominan yang ditemukan adalah Aphis craccivora dengan persentase serangan berkisar 20\% - 90\%. Jenis aphidophaga dan coccidophaga lain yang ditemukan yaitu dari Ordo Coleoptera : Famili Coccinellidae: Menochilus sexmaculatus, Micraspis sp., Harmonia sp., Verania lineata, Curinus coeruleus, Scymnus sp., Coccinella transversalis; Ordo Diptera : Famili Syrphidae yaitu Ischiodon scutellaris, Neuroptera : Famili Hemerobiidae; Ordo Diptera : Famili Cecidomyiidae Aphidoletes aphidimyza; serta terdapat pula kumbang Carabidae dari Ordo Coleoptera dengan indeks keragaman spesies yang masih tergolong rendah. Kelimpahan tertinggi predator dari kelompok aphidophaga dan coccidophaga didominasi oleh spesies Ischiodon scutellaris dan Menochilus sexmaculatus.
\end{abstract}

Kata kunci : Keragaman, Kelimpahan, Spesies dominan, Serangga hama 


\section{PENDAHULUAN}

Dalam suatu agroekosistem, keragaman hayati sangat diperlukan untuk meningkatkan produksi tanaman. Keragaman hayati menggambarkan tingkat banyaknya jenis (famili atau spesies) organisme di dalam komunitas (Groombridge 1992; Subagja 1996; Krebs 1999) dan sebagai konsep yang mengacu kepada kisaran variasi biotik di alam yang digunakan untuk menjelaskan jumlah variasi organisme hidup, sehingga sering dikatakan keragaman hayati merupakan salah satu unsur yang selalu ada dan sebagai unsur kehidupan di alam (Subagja 1996). Keragaman hayati mempunyai arti yang sangat penting, baik sebagai sumber daya maupun dalam pemeliharaan ekosistem Pada ekosistem yang seimbang tidak ada satu jenis organisme yang menjadi dominan dan populasinya menonjol dibandingkan dengan populasi organisme lain (Untung, 1996). Di dalam ekosistem termasuk agroekosistem kacang panjang, arthropoda termasuk serangga bukan hanya sebagai herbivor maupun detretivor, melainkan menempati kedudukan dan fungsi yang dinamis. Oleh karena itu arthropoda termasuk serangga sangat berperan dalam menjaga terjadinya keseimbangan atau kestabilan ekosistem.

Menurut Untung (2006), serangga paling cepat memberikan tanggapan dan sekaligus mempunyai daya adaptasi tinggi terhadap berbagai bentuk tekanan lingkungan termasuk tindakan pengendalian hama dengan insektisida. Serangga merupakan komponen yang dominan dalam suatu agroekosistem dan dapat memengaruhi hasil pertanian. Secara taksonomi kelompok serangga pemakan kutu-kutuan (aphidophaga atau coccidophaga) dapat berasal dari berbagai kelompok yang berbeda, baik ordo maupun famili, namun umumnya dalam istilah ekologi masuk dalam satu guild (organisme yang membutuhkan sumberdaya yang sama dan mengekploitasi dengan cara yang sama pula). Beberapa contoh ordo dan famili yang masuk dalam kelompok aphidophaga dan coccidophaga yang bersifat sebagai predator adalah Coccinellidae (Coleoptera), Syrphidae, Cecidomyiidae, dan Chamaemyiidae (Diptera), Chrysophidae dan Hemerobiidae (Neuroptera). Adanya keragaman dalam suatu agroekosistem ini menyebabkan terjadinya interaksi antara serangga fitophaga dan serangga entomophaga sehingga dapat menjaga keseimbangan ekosistem yang sesuai dengan konsep PHT. Konsep dasar PHT yaitu berlandaskan pada pendekatan ekologi dan lingkungan dengan harapan terjadinya keseimbangan populasi antara serangga hama dan kompleks musuh alaminya sehingga terciptanya pertanian yang berkelanjutan (Untung, 2006). Adapun kegiatan yang menggunakan prinsip ekologi tersebut diantaranya yaitu dengan melakukan penelitian mengenai pemantauan (monitoring/pengamatan) terhadap keragaman dan kelimpahan entomophaga seperti aphidophaga dan coccidophaga yang menghuni agroekosistem pertanaman kacang panjang di Kabupaten Garut.

Untuk kelompok serangga yang pada umumnya menjadikan kutu daun (aphid) sebagai inang atau mangsa, biasa disebut aphidophaga. Sementara untuk pemakan kutu-kutuan lainnya, seperti Coccidae, Pseudococcidae, Diaspididae, biasa disebut coccidophaga. Serangga yang termasuk ke dalam kelompok aphidophaga dan cocidophaga tersebut memiliki diversitas (keragaman) spesies yang cukup tinggi. Salah satu famili serangga dari kelompok aphidophaga dan cocidophaga yaitu famili coccinellidae. Serangga yang termasuk famili Coccinellidae tersebut diperkirakan ada 5000 spesies di seluruh dunia (Foltz, 2002).

Berdasarkan penelusuran literatur yang dilakukan, belum pernah dilaporkan tentang keragaman dan kelimpahan aphidophaga dan coccidophaga di sekitar pertanaman kacang panjang di Kabupaten Garut. Menurut Holling (1961), keberadaan predator pada suatu kawasan sangat terkait dengan keberadaan mangsanya. Oleh sebab itu, dipandang perlu untuk melakukan penelitian tentang keragaman dan kelimpahan aphidophaga dan coccidophaga di sekitar pertanaman kacang panjang di Kabupaten Garut.

Penelitian ini bertujuan untuk mengkaji serta menganalisis keragaman dan kelimpahan aphidophaga dan coccidophaga yang terdapat di agroekosistem tanaman kacang panjang sehingga diharapkan dapat mengoptimalkan peran musuh alami (aphidophaga dan coccidophaga) tersebut dalam rangka mendukung sistem pertanian berkelanjutan di Kabupaten Garut.

\section{METODE PENELITIAN}

Penelitian ini dilakukan dengan cara pengamatan di lapangan dan pengamatan di laboratorium. Pengamatan lapangan dilaksanakan di salah satu daerah sentra produksi tanaman kacang panjang di Kabupaten Garut, sedangkan pengamatan laboratorium dilaksanakan di laboratorium Entomologi Jurusan Hama dan Penyakit Tumbuhan Fakultas Pertanian Universitas Padjadjaran. 
Penelitian dilakukan dari bulan April sampai November 2011. Pengamatan lapangan dilakukan dengan menggunakan metode survei yang dilaksanakan dengan cara:

1. Observasi terhadap agroekosistem pertanaman kacang panjang.

2. Pengamatan hama A. craccivora Koch., dan kutu daun $M$. persicae, serta keragaman dan kelimpahan aphidophaga dan coccidophaga

3. Pengumpulan sampel dengan melakukan pengambilan secara langsung pada tanaman sampel yang dilakukan terhadap spesies aphidophaga dan coccidophaga yang memang menghabiskan sebagian atau seluruh siklus hidupnya langsung pada bagian tanaman kacang, pemasangan perangkap dan penggunaan jaring ayun (sweeping net).

Penentuan petak sampel ditentukan secara purposif dan proporsional yaitu 10\% dari seluruh tanaman pada lahan sampel. Pemasangan perangkap diletakkan secara sistematik dengan sistem diagonal sebanyak lima buah. Perangkap ini diamati dan diganti seminggu sekali. Pengambilan sampel menggunakan sweeping net dilakukan dengan sepuluh kali ayunan pada titik-titik yang telah ditentukan secara diagonal sistematis.

Pengambilan sampel serangga dilakukan sekali seminggu selama tiga kali pengambilan. Serangga yang diperoleh diambil dan disimpan dalam botol koleksi yang berisi larutan alkohol 70\% dan telah diberi label (hari/tanggal, lokasi, alat koleksi) selanjutnya dibawa ke Laboratoriun Entomologi Departemen Hama dan Penyakit Tumbuhan Fakultas Pertanian Unpad untuk disortasi dan diidentifikasi. Seluruh sampel yang diperoleh di lapangan disortasi untuk memisahkan serangga berdasarkan ordo-ordo, kemudian diidentifikasi dengan cara memperhatikan ciri-ciri morfologi dibawah mikroskop binokuler lalu diidentifikasi dengan menggunakan kunci identifikasi serangga (Borror et al., 1992) dan The Insect of Australia (Carver et al., 1996). Berbagai jenis serangga predator yang diperoleh dihitung jumlahnya dan dianalisis dengan menggunakan perhitungan Indeks Keragaman Shannon-Wienner dengan menggunakan rumus berikut (Wilson \& Bossert, 1971 dalam Oka, 2005):

$\mathrm{H}^{\prime}=-\sum_{i=1}^{n} \mathrm{Pi} \ln \mathrm{Pi}$

Keterangan:

$\mathrm{H}^{\prime} \quad$ = Indeks Keragaman
$\mathrm{Pi} \quad=$ Proporsi semua individu sampel menjadi bagian spesies ke $(\mathrm{i})(\mathrm{Pi}=\mathrm{ni} / \mathrm{N})$

ni $\quad=$ Jumlah total individu spesies ke (i)

$\mathrm{N} \quad=$ Jumlah total individu spesies

Penilaian terhadap indeks keragaman yang diperoleh menggunakan aturan Rahmawaty (2000) dalam Syahrawati \& Hamid (2010) dengan kategori keragaman sebagai berikut:

$\begin{array}{ll}1,5 & =\text { Keragaman rendah } \\ 1,5-3,5 & =\text { Keragaman sedang } \\ >3,5 & =\text { Keragaman tinggi }\end{array}$

\section{HASIL DAN PEMBAHASAN}

\section{Kondisi Umum Lahan}

Sistem pertanian di Kecamatan Leles adalah polikultur. Tanaman kacang panjang ditanam di lahan kering dan sering dijadikan sebagai rotasi tanaman. Tanaman kacang panjang yang dijadikan sampel ditumpangsarikan dengan tanaman cabai keriting, terung, dan tomat. Di samping itu, tanaman kacang panjang juga ditanam pada bedengan dengan menggunakan mulsa plastik, dan tanpa dilakukan penyiangan terhadap gulma yang tumbuh dilekukan antar bedengan. Beberapa kali petani melakukan penyemprotan pestisida sintetik misalnya Dursban. Pengambilan sampel dilakukan pada saat tanaman telah memasuki fase generatif.

\section{Komposisi Serangga pada Agroekosistem Kacang Panjang}

Berdasarkan pengamatan yang telah dilakukan, berhasil dikoleksi 6.799 individu yang terdiri dari 33 jenis serangga dan 1 jenis laba-laba yang diperoleh di agroekosistem pertanaman kacang panjang di lokasi penelitian. Dari hasil koleksi tersebut, berhasil diidentifikasi 11 jenis hama, 18 jenis predator, 4 jenis parasitoid, dan 1 jenis detritivor (Tabel 1). Hasil pengamatan menunjukkan adanya serangan hama $A$. craccivora yang yang mendominasi dan selalu berada pada bagian tanaman yang terserang, sedangkan populasi hama $M$. persicae tidak ditemukan. Serangan $A$. craccivora terjadi pada bagian polong, daun serta batang dengan persentase serangan paling tinggi terjadi pada daun dan polong.

Persentase serangan pada saat pengamatan di lahan berkisar antara 20\% - 90\%. Hal ini menunjukkan bahwa pada saat pengamatan populasi A. craccivora bervariasi di lahan sampel. Kutu daun (Aphis craccivora) menyerang pada awal pertumbuhan dan masa pertumbuhan bunga dan 
polong (Warintek Bantul, 2009). Biasanya serangan terjadi pada pucuk tanaman, menyebabkan tanaman menjadi layu dan pertumbuhan terhambat. Populasi A. craccivora pada saat pengamatan cukup tinggi dengan banyak ditemukannya alate (individu yang bersayap) menunjukkan bahwa populasinya cukup padat, hal ini disebabkan karena kondisi cuaca di lahan pada saat pengamatan kering dan tidak turun hujan sehingga kondisi demikian cocok untuk perkembangan A. craccivora. Hama lain yang banyak ditemukan dan memiliki mobilitas yang cukup tinggi di lahan adalah lalat buah Bactrocera dorsalis. Hal ini dikarenakan pada lahan sampel ditumpangsarikan dengan berbagai komoditas tanaman diantaranya cabai, terung, dan tomat, yang merupakan inang dari hama tersebut dan kemungkinan berasosiasi dengan tanaman tumpangsari disekitarnya.

Tabel 1. Komposisi dan status serangga yang dikoleksi dari agroekosistem kacang panjang di Kecamatan Leles Kabupaten Garut.

\begin{tabular}{|c|c|c|}
\hline No & Jenis & Status \\
\hline 1. & Aphis craccivora (Homoptera: Aphididae) & Hama \\
\hline 2. & Lalat buah - Bactrocera dorsalis (Diptera: Tephritidae) & Hama \\
\hline 3. & Lalat hijau - Lucilia sericata (Diptera: Calliphoridae) & Hama \\
\hline 4. & Lalat kacang Agromyza phaseoli (Diptera: Agromyzidae) & Hama \\
\hline 5. & Empoasca sp (Homoptera: Cicadellidae) & Hama \\
\hline 6. & Riptortus linearis (Hemiptera: Alydidae) & Hama \\
\hline 7. & Oxya sp (Orthoptera: Acrididae) & Hama \\
\hline 8. & Thrips sp (Thysanoptera: Thripididae) & Hama \\
\hline 9. & Diaprepes abbreviates (Coleoptera : Curculionidae) & Hama \\
\hline 10. & (Homoptera: Pseudococcidae) & Hama \\
\hline 11. & Lepidoptera & Hama \\
\hline 12. & Colembola & Detritivor \\
\hline 13. & Fire ant- Solenopsis sp. (Hymenoptera: Formicidae) & Predator ${ }^{*}$ \\
\hline 14. & Black ant- Dolichoderus sp (Hymenoptera: Formicidae) & Predator* \\
\hline 15. & Metioche vittaticollis (Orthoptera : Gryllidae) & Predator \\
\hline 16. & Aeshna grandis (Odonata : Aeshnidae) & Predator \\
\hline 17. & Oxyopes javanus (Araneae : Oxyopidae) & Predator \\
\hline 18. & Menochilus sexmaculatus (Coleoptera : Coccinellidae) & Predator \\
\hline 19. & Micraspis sp. (Coleoptera : Coccinellidae) & Predator \\
\hline 20. & Ischiodon scutellaris (Diptera; Syrphidae) & Predator \\
\hline 21. & Harmonia sp. (Coleoptera : Coccinellidae) & Predator \\
\hline 22. & Scymnus sp. (Coleoptera : Coccinellidae) & Predator \\
\hline 23. & Coccinella transversalis sp. (Coleoptera : Coccinellidae) & Predator \\
\hline 24. & Neuroptera (Hemerobiidae) & Predator \\
\hline 25. & Verania lineata (Coleoptera : Coccinellidae) & Predator \\
\hline 26. & Curinus coeruleus (Coleoptera: Coccinellidae) & Predator \\
\hline 27. & Diplacodes haematodes (Odonata : Libellulidae) & Predator \\
\hline 28. & Coleoptera (Carabidae) & Predator \\
\hline 29. & Aphidoletes aphidimyza (Diptera :Cecidomyiidae) & Predator \\
\hline 30. & Exorista sp. (Diptera : Tachinidae) & Parasitoid \\
\hline 31. & Trioxys sp. (Hymenoptera; Aphididae) & Parasitoid \\
\hline 32. & Aphelinus sp. (Hymenoptera; Aphelinidae) & Parasitoid \\
\hline 33. & (Hymenoptera : Ichneumonidae) & Parasitoid \\
\hline
\end{tabular}


Serangga Predator pada Agroekosistem Kacang jenis predator (Tabel 2). Sebagian besar predator Panjang yang ditemukan dan berhasil diidentifikasi tersebar Setelah dilakukan separasi data, ditemukan 6.768 individu serangga predator yang terdiri dari 18 dalam kelompok aphidophaga, coccidopaga, dan predator yang bersifat generalis atau umum.

Tabel 2. Keragaman dan kelimpahan serangga predator pada agroekosistem kacang panjang di Desa Haruman Kecamatan Leles Kabupaten Garut

\begin{tabular}{|c|c|c|c|c|c|}
\hline \multirow{3}{*}{ No } & \multirow{3}{*}{ Takson } & \multirow{2}{*}{\multicolumn{3}{|c|}{$\begin{array}{l}\text { Jumlah Serangga yang } \\
\text { Tertangkap (Ekor) } \\
\text { Umur tanaman (HST) }\end{array}$}} & \multirow[t]{3}{*}{$\begin{array}{l}\text { Total } \\
\text { (ekor) }\end{array}$} \\
\hline & & & & & \\
\hline & & 35 & 42 & 49 & \\
\hline 1. & Menochilus sexmaculatus (Coleoptera : Coccinellidae) & 248 & 213 & 179 & 640 \\
\hline 2. & Micraspis sp. (Coleoptera : Coccinellidae) & 0 & 2 & 0 & 2 \\
\hline 3. & Ischiodon scutellaris (Diptera; Syrphidae) & 307 & 239 & 202 & 748 \\
\hline 4. & Harmonia sp. (Coleoptera : Coccinellidae) & 3 & 4 & 0 & 7 \\
\hline 5. & Neuroptera (Hemerobiidae) & 65 & 50 & 58 & 173 \\
\hline 6. & Dolichoderus sp. (Hymenoptera :formicidae) & 2309 & 1605 & 569 & 4483 \\
\hline 7. & Solenopsis sp. (Hymenoptera : formicidae) & 280 & 133 & 78 & 491 \\
\hline 8. & Verania lineata (Coleoptera : Coccinellidae) & 2 & 0 & 1 & 3 \\
\hline 9. & Curinus coeruleus (Coleoptera: Coccinellidae) & 2 & 3 & 0 & 5 \\
\hline 10. & Oxyopes javanus (Araneae : Oxyopidae) & 8 & 15 & 9 & 32 \\
\hline 11. & Scymnus sp. (Coleoptera: Coccinellidae) & 1 & 1 & 0 & 2 \\
\hline 12. & Aphidoletes aphidimyza (Diptera :Cecidomyiidae) & 26 & 19 & 12 & 57 \\
\hline 13. & Coccinella transversalis (Coleoptera: Coccinellidae) & 1 & 2 & 0 & 3 \\
\hline 14. & Diplacodes haematodes (Odonata : Libellulidae) & 1 & 0 & 2 & 3 \\
\hline 15. & Coleoptera (Carabidae) & 38 & 38 & 20 & 96 \\
\hline 16. & Menochilus sexmaculatus (Coleoptera : Coccinellidae) & 248 & 213 & 179 & 640 \\
\hline 17. & Diptera (Asilidae) & 3 & 2 & 0 & 5 \\
\hline 18. & Aeshna grandis (Odonata: Aeshnidae) & 3 & 1 & 1 & 5 \\
\hline \multicolumn{2}{|c|}{ Jumlah Jenis Takson } & 17 & 16 & 11 & 18 \\
\hline \multicolumn{2}{|c|}{ Total Individu } & 3300 & 2332 & 1136 & 6768 \\
\hline \multicolumn{2}{|l|}{$\mathrm{H}^{\prime}$} & 1,09 & 1,15 & 1,49 & \\
\hline \multicolumn{2}{|l|}{ E } & 0,39 & 0,42 & 0,62 & \\
\hline \multicolumn{2}{|l|}{$\mathrm{D}$} & 0,51 & 0,49 & 0,31 & \\
\hline \multicolumn{6}{|c|}{ Keterangan : } \\
\hline HST & \multicolumn{5}{|l|}{$=$ Hari setelah tanam } \\
\hline $\mathrm{H}$ & \multicolumn{5}{|l|}{ = Indeks Keragaman Shannon-Weanner } \\
\hline $\mathrm{E}$ & \multicolumn{5}{|l|}{ = Indeks sebaran Keragaman Shannon (Evenness) } \\
\hline $\mathrm{D}$ & \multicolumn{5}{|l|}{ = Kelimpahan (indeks Simpson) } \\
\hline
\end{tabular}

Berdasarkan hasil analisis data mengenai keragaman spesies predator, didapatkan nilai indeks keragaman Shanon-Wiener $\left(\mathrm{H}^{`}\right)$ pada pengamatan ke- 35, 42, dan 49 HST berturut-turut yaitu 1,09; 1,15 ; dan 1,49. Angka ini menunjukkan bahwa keragaman predator pada agroekosistem kacang panjang secara keseluruhan tergolong masih rendah (Tabel 2). Selain itu dari tabel 2 juga diperoleh bahwa nilai kemerataan atau nilai sebaran keragaman Shannon (Evenness) predator pada agroekosistem kacang panjang juga rendah. Pada pengamatan ke- 35, 42, dan 49 HST nilai indeks sebaran keragaman Shannon berturut-turut yaitu 0,$39 ; 0,42$; dan 0,62 dan dari nilai kelimpahan pada setiap pengamatan berdasarkan indeks Simpsons yaitu 0,$51 ; 0,49 ; 0,31$. Nilai ini menunjukkan ketidakmerataan spesies pada suatu komunitas. Hal ini ditunjukkan dengan dominasi dari suatu populasi predator dan dilihat yang paling banyak ditemukan 
adalah Dolichoderus sp. (Formicidae: Hymenoptera) yang dikenal dengan nama semut hitam.

Semut merupakan predator yang cukup efektif untuk mengendalikan telur-telu serangga dan ulat daun, namun perlu mendapatkan perhatian karena jika dilihat dari tingginya populasi serangga A. craccivora, maka keberadaan semut ini harus diwaspadai karena bukan pada posisi mempredasi namun justru bekerjasama secara mutualisme atau saling menguntungkan. Borror et al. (1992) menyatakan bahwa serangga jenis Aphid dipelihara oleh semut. Aphid muda hidup disarang semut dan diantarkan semut ke tanaman inangnya sehingga Aphid dengan mudah menemukan inangnya. Sedangkan semut mendapatkan hasil sekresi Aphid berupa embun madu. Sehingga di sekitar aktivitas kutu daun tersebut banyak terlihat adanya embun jelaga yang mendukung untuk perkembangan cendawan Capnodium sp. yang tumbuh pada sekresi atau kotoran kutu daun berupa embun madu.

Keragaman dan Kelimpahan Aphidophaga dan Coccidophaga pada Agroekosistem Kacang Panjang
Dari hasil identifikasi ditemukan 11 jenis predator yang termasuk ke dalam aphidophaga dan coccidophaga dan 7 jenis predator yang bersifat generalis. Predator yang termasuk ke dalam kelompok aphidophaga dan coccidophaga didominasi oleh Ordo Coleoptera sebanyak 72,73\% dan $87,5 \%$ di dalamnya didominasi oleh spesiesspesies dari Famili Coccinellidae.

Predator yang termasuk kelompok aphidophaga dan coccidophaga yang ditemukan dianaranya yaitu : Menochilus sexmaculatus, Micraspis sp., Harmonia sp., Verania lineata, Curinus coeruleus, Scymnus sp., Coccinella transversalis. Larva dan imago dari kumbang Coccinelidae ini banyak memangsa $A$. craccivora. Selain itu, ada pula dari Ordo Diptera : Famili Syrphidae yaitu Ischiodon scutellaris yang biasa disebut lalat apung atau hover fly, dan dari Ordo Neuroptera : Famili Hemerobiidae yang larvanya banyak dijumpai sedang aktif memangsa $A$. craccivora, Aphidoletes aphidimyza (Diptera : Cecidomyiidae), serta terdapat pula kumbang Carabidae dari Ordo Coleoptera (Tabel 3).

Tabel 3. Keragaman dan Kelimpahan Ahidophaga dan Coccidophaga pada Agroekosistem Kacang Panjang di Desa Haruman Kecamatan Leles, Kabupaten Garut.

\begin{tabular}{|c|c|c|c|c|c|}
\hline \multirow{3}{*}{ Nomor } & \multirow{3}{*}{ Takson } & \multirow{2}{*}{\multicolumn{3}{|c|}{$\begin{array}{l}\text { Jumlah Serangga yang } \\
\text { Tertangkap * (Ekor) } \\
\text { Umur tanaman (HST) }\end{array}$}} & \multirow{3}{*}{ Total (ekor) } \\
\hline & & & & & \\
\hline & & 35 & 35 & 35 & \\
\hline 1. & Menochilus sexmaculatus (Coleoptera : Coccinellidae) & 248 & 213 & 179 & 640 \\
\hline 2. & Micraspis sp. (Coleoptera : Coccinellidae) & 0 & 2 & 0 & 2 \\
\hline 3. & Ischiodon scutellaris (Diptera; Syrphidae) & 307 & 239 & 202 & 748 \\
\hline 4. & Harmonia sp. (Coleoptera : Coccinellidae) & 3 & 4 & 0 & 7 \\
\hline 5. & Neuroptera (Hemerobiidae) & 65 & 50 & 58 & 173 \\
\hline 6. & Verania lineata (Coleoptera : Coccinellidae) & 2 & 0 & 1 & 3 \\
\hline 7. & Curinus coeruleus (Coleoptera: Coccinellidae) & 2 & 3 & 0 & 5 \\
\hline 8. & Scymnus sp. (Coleoptera: Coccinellidae) & 1 & 1 & 0 & 2 \\
\hline 9. & Aphidoletes aphidimyza (Diptera :Cecidomyiidae) & 26 & 19 & 12 & 57 \\
\hline 10. & Coccinella transversalis (Coleoptera: Coccinellidae) & 1 & 2 & 0 & 3 \\
\hline 11. & Coleoptera (Carabidae) & 38 & 38 & 20 & 96 \\
\hline \multicolumn{2}{|c|}{ Jumlah Jenis Takson } & 10 & 10 & 6 & 11 \\
\hline \multicolumn{2}{|c|}{ Total Individu } & 693 & 571 & 472 & 1736 \\
\hline \multicolumn{2}{|l|}{ H' } & 1,31 & 1,35 & 1,23 & \\
\hline \multicolumn{2}{|l|}{$\mathrm{E}$} & 0,57 & 0,59 & 0,69 & \\
\hline \multicolumn{2}{|l|}{$\mathrm{D}$} & 0,34 & 0,33 & 0,34 & \\
\hline \multicolumn{6}{|c|}{ Keterangan : } \\
\hline $\mathrm{HST}=$ & \multicolumn{5}{|l|}{$=$ Hari setelah tanam } \\
\hline $\mathrm{H}^{\prime}$ & \multicolumn{5}{|l|}{$=$ Indeks Keragaman Shannon-Weanner } \\
\hline $\begin{array}{l}\text { E } \\
D\end{array}$ & \multicolumn{3}{|l|}{ = Indeks sebaran Keragaman Shannon (Evenness) } & \multicolumn{2}{|c|}{$=$ Kelimpahan (indeks Simpson) } \\
\hline
\end{tabular}


Secara umum jika melihat dari Tabel 3, nilai indeks keragaman Shanon-Wiener $\left(\mathrm{H}^{\prime}\right)$ pada pengamatan ke- 35, 42, 49 HST berturut-turut yaitu 1,$31 ; 1,35$; dan 1,23, menunjukkan bahwa keragaman serangga aphidophaga dan coccidophaga pada agroekosistem kacang panjang di Kecamatan Leles masih tergolong rendah. Rendahnya nilai indeks keragaman ini menyebabkan rendahnya nilai kemerataan atau indeks sebaran keragaman pada lahan sampel pada tiap pengamatan yaitu 0,57; 0,59; dan 0,69. Hal ini ditunjukkan dengan dominasi populasi dari spesies Ischiodon scutellaris (Diptera; Syrphidae) dan Menochilus sexmaculatus (Coleoptera : Coccinellidae). Kelimpahan tertinggi serangga aphidophaga dan coccidophaga di Desa Haruman Kecamatan Leles yaitu Ischiodon scutellaris (Diptera; Syrphidae) sebanyak 748 individu dan Menochilus sexmaculatus (Coleoptera : Coccinellidae) sebanyak 640 individu. Sedangakan kelimpahan terendah yaitu Micraspis sp. dan Coccinella transversalis sebanyak 2 individu.

Jika dibandingkan dengan nilai sebaran keragaman Shannon pada serangga predator secara umum (Tabel 2), nilai sebaran keragaman Shannon pada serangga aphidophaga dan cociidophaga pada tabel 3 lebih tinggi yang berarti sebarannya lebih merata. Nilai sebaran keragaman Shannon berkisar dari nol sampai satu, jika sebaran keragaman Shannon mendekati nol, maka distribusi patch dalam plot tidak merata, tetapi jika mendekati satu, maka distribusi patch lebih merata (Elkie et al. 1999). Menurut Ludwig \& Renolds (1998), nilai sebaran keragaman Shannon ini akan mempengaruhi keragaman spesies suatu komunitas.Menurut Quicke (1997), nilai kompleksitas suatu daerah dikatakan tinggi jika daerah itu disusun oleh vegetasi yang beragam. Habitat yang beragam dalam pengertian memiliki jenis tanaman yang banyak pada suatu daerah menyediakan sumber daya yang mendukung kehidupan serangga. Tanaman yang beranekaragam pada suatu wilayah dapat mengurangi persaingan antar spesies sehingga keberhasilan hidup serangga disuatu wilayah lebih terjamin. Van Emdem (1991) menyatakan peningkatan keragaman habitat pada suatu kawasan pertanian dapat meningkatkan keragaman serangga hama dan serangga bermanfaat (musuh alami) dan mengurangi kerusakan tanaman oleh hama.

Ketidakmerataan spesies aphidophaga dan coccidophaga ini mungkin juga disebabkan karena pemakaian pestisida oleh petani dan penggunaan mulsa plastik hitam perak sehingga keberadaan gulma berkurang. Tumbuhan liar semisal gulma merupakan komponen agroekosistem yang penting, karena secara positif dapat mempengaruhi biologi dan dinamika musuh alami (Altieri \& Nicholls, 2004). Tumbuhan liar yang tumbuh di sekitar pertanaman tidak hanya berfungsi sebagai tempat berlindung (shelter) dan pengungsian musuh alami ketika kondisi lingkungan tidak sesuai (van Emdem, 1991), tetapi juga menyediakan inang alternatif dan makanan tambahan seperti tepung sari dan nektar dari tumbuhan berbunga serta embun madu yang dihasilkan oleh ordo Homoptera (Altieri dan Nicholls 2004). Gulma juga dapat berperan sebagai inang pengganti bagi musuh alami apabila jumlah tanaman inang utama hilang atau berkurang. Keberadaan gulma juga dapat meningkatkan keragaman dan kelimpahan musuh alami.

Selain aphidophaga dan coccidophaga juga ditemukan predator Arachnida atau laba-laba yang dikenal sebagai "predator segala". Laba-laba merupakan predator polifag sehingga berperan penting dalam mengontrol populasi serangga. Capung A. grandis juga diketahui bahwa pada setiap tahapan hidupnya adalah predator dengan kisaran mangsa yang luas (Borror et al, 1992). Pada lahan sampel kacang panjang juga ditemukan serangga ordo Orthoptera famili Gryllidae (jangkrik). Jangkrik dapat menjadi predator bagi telur serangga. Pada umumnya, jangkrik suka memakan telur atau serangga lain seperti ulat atau kutu (Kalshoven, 1981).

\section{SIMPULAN}

Berdasarkan hasil penelitian, dapat disimpulkan bahwa :

1. Serangga hama yang dominan ditemukan pada agroekositem kacang panjang yaitu $A$. craccivora dengan persentase serangan berkisar $20 \%$ sampai $90 \%$, dan serangan $A$. craccivora paling tinggi terjadi pada polong dan daun.

2. Serangga predator yang ditemukan terdiri dari 18 jenis predator. Sebagian besar predator yang ditemukan dan berhasil diidentifikasi tersebar dalam kelompok aphidophaga, coccidopaga, dan predator yang bersifat generalis atau umum.

3. Predator yang termasuk kelompok aphidophaga dan coccidophaga yang ditemukan diantaranya yaitu : Ordo Coleoptera : Famili Coccinellidae Menochilus sexmaculatus, Micraspis sp., Harmonia sp., Verania lineata, Curinus coeruleus, Scymnus sp., Coccinella transversalis; 
Ordo Diptera : Famili Syrphidae yaitu Ischiodon scutellaris; Neuroptera : Famili Hemerobiidae; Ordo Diptera : Famili Cecidomyiidae Aphidoletes aphidimyza; serta terdapat pula kumbang Carabidae dari Ordo Coleoptera.

4. keragaman serangga aphidophaga dan coccidophaga pada agroekosistem kacang panjang di Kecamatan Leles masih tergolong rendah yang ditunjukkan dengan dominasi populasi dari spesies Ischiodon scutellaris (Diptera; Syrphidae) dan Menochilus sexmaculatus (Coleoptera : Coccinellidae).

\section{UCAPAN TERIMA KASIH}

Penulis mengucapkan terima kasih kepada DIPA BLU Universitas Padjadjaran dan Lembaga Penelitian dan Pengabdian Kepada Masyarakat Universitas Padjadjaran yang telah mendanai penelitian ini dengan nomor kontrak 1352/UN6.R/PL/2011.

\section{DAFTAR PUSTAKA}

Altieri MA, Nicholls CI. 2004. Biodiversty and Pest Management in Agroecosystem. Second Edition. New York: Chapman and Hall.

Badan Pusat Statistik. 2009. Produksi Sayuran di Indonesia. http://bps.go.id. Diakses 8 Februari 2011.

Borror, DJ, Triplehorn, dan Johnson. 1992. Pengenalan Pelajaran Serangga $6^{\text {th }}$. Gadjah Mada University Press. Yogyakarta

Carver M, Gross GF, and Woodword TE. 1991. The Insect of Australia. CSIRO. Australia.

Elkie PC, Rempel RS, Carr Ap. 1999. Pacth Analyst User's Manual: A Tool for Quantifiying Landscape. Ontario; Queen's Printer for Ontario.

Foltz, J.L. 2002. Coleoptera: Coccinellidae. Dept of Entomology \& Nematology. University of Florida.

http://entomology.ifas.ufl.edu/foltz/eny3005 /lab1/ Coleoptera/Coccinelid.htm. Diakses 8 Januari 2011.

Groombridge B. 1992. Global diversity. Status of the earths living resources. Chapmann \& Hall. London. 585p.

Holling, C. S., 1961. Principles of Insect Predation. Ann. Rev. Entomol. 6 : 163-182.

Julinatono, J. 2009. Mengenal Predator diantara Hama Serangga. http://www.tanindo.com/ abdi10/hal3001.htm. Diakses 5 Februari 2011.

Kalshoven, L.G.E. 1981. Pest of Crops in Indonesia. Ichtiar Baru - Van Hoeve. Jakarta.

Krebs, C.J. 1999. Ecological Metodology. Second Edition. New York; An Imprint of Addition Wesley Longman, Inc.

Ludwig JA, Reynold JF. 1998. Statistical Ecology. New York: Jhon Wiley \& Sons.

Oka. I. N. 2000. Pengendalian Hama Terpadu dan Implementasinya di Indonesia. Gadjah Mada University Press. Yogyakarta.

Quicke, D.L.J. 1997. Parasitic Wasps. Chapman\& Hall.

Subagja, J., 1996. Prinsip Keanekaragaman Hayati dalam Ekosistem Prosiding Makalah Utama Seminar Nasional Pengendalian Hayati (SNPH), Yogyakarta.

Syahrawati, M dan Hamid H. 2010. Diversitas Coccinellidae Predator pada Pertanaman Sayuran di Kota Padang. repository.unand.ac.id/6412/1/artkl_mysyah rawati.pdf. Diakses 28 Januari 2011.

Untung K. 2006. Pengantar Pengelolaan Hama Terpadu. Ed ke-2. Yogyakarta. Gadjah Mada University Press.

Van Emdem, HF. 1991. Plant Diversity and Natural Enemy Efficiency in Agroecosystem. Di dalam: Mackkauer M, Ehler L E, Roland J, editor. Critical Issue in Biological Control. Great Britain: Atheneum Press.

Warintek $\quad$ Bantul. $2009 . \quad$ Kedelai. http://warintek.bantulkab.go.id. Diakses 28 Januari 2011. 